\title{
Knowledge Transfer Mechanisms Involved In The Reactive Production Capacity Of The Jalisco, Mexico, Cluster Of Electronic Manufacturing
}

Miguel Estrada Guzmán, Universidad Anáhuac México Sur, Mexico

\begin{abstract}
The development of the electronic manufacturing cluster in Guadalajara, Jalisco, has become one of the most important spearheads of Mexico's industrial strategy. The knowledge transfer process in the region has enabled the growth of global supply chains by making them more agile, adaptable, and aligned in order to meet the requirements of technological products whose demand remains highly uncertain. The reactive capacity of supply chains towards market conditions has increased local competitiveness with lower labor costs compared with operations in other parts of the world. Through a review of literature related to supply chain and knowledge management, in addition to the analysis of case studies and industry reports, it is possible to identify some conditions that have empowered the development of knowledge and some mechanisms by which it has been transferred inside the cluster. The importance of understanding the knowledge transfer inside the cluster lies in its potential to be applied to other sectors or regions.
\end{abstract}

Keywords: knowledge management; supply chain; technology convergence; outsourcing; cluster

\section{INTRODUCTION}

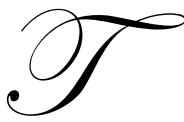

he electronic manufacturing cluster in Guadalajara Jalisco, in Mexico's Western region, has become the spearhead of Mexico's industrial strategy. The cluster's relevance is a result of the improvement it brings to the economy and the labor market. Allegedly, the cluster's ability to add value to its supply chains has evolved so its study becomes even more attractive, particularly given its possible application to other sectors or regions in the Mexican industry. Part of the cluster's importance lies in its potential integration into global chains among original equipment manufacturers (OEM), contract electronic manufacturing (CEM), and the region's local suppliers.

Nowadays the globalization of complex production supply chains not only represents a way to increase the company's productivity, compared to traditional operations, but also "it has emerged as one of the main company areas to gain competitive advantages" (Lee H., 2004). It is said that the best value supply chains are key competitive weapons for the 21 st century (Ketchen, Rebarick, Hult, \& Meyer, 2008). Business trends of the 1990s, related to more complex and globalized operations, created in an uncertain world the need for supply chain management and advances in information technology (Kopczack, 2003). New theories related to collaboration between companies to reduce the bullwhip effect helped to create a new context.

Supply chains are not static but constantly should evolve to respond, in a more agile, adaptable and aligned way, to demand (Lee H., 2004). In the electronic manufacturing sector, the development of new technologies applied to consumer products, as well as the technological convergence of devices has led to shortened product life-cycles with increasing levels of demand uncertainty. The ability to react to demand becomes a strategic issue which is outlined by two main conditions i) the global supply chain design and ii) the ability of knowledge development and share in each link of the supply chain. The idea that link-companies in the supply chain do not compete individually but rather as a whole is commonly accepted. 
Understanding the mechanisms by which knowledge is transferred within the electronics manufacturing cluster in Guadalajara becomes a fundamental aspect; such awareness would allow its replication in other regions (North and Northwestern Mexico, Central America or the Caribbean) or in other sectors with short life-cycle products such as clothing, appliances, medical instruments, etc.

This paper intends to identify some knowledge transfer mechanisms used by supply chains in their aim to evolve within the electronics manufacturing cluster in Guadalajara, Jalisco.

\section{The Global Or Local Knowledge Sharing Dilemma}

The kind of knowledge must be relevant to the way in which the specific companies-links compete inside a supply chain that competes as a whole. Each company-link in the supply chain can offer specific capabilities that are acquired locally, for that reason it is also common that CEM competitors, in the same region, share similar characteristics in their production strategies, which could be developed with similar kinds of knowledge.

To achieve regional development, the cluster must provide various supply chains with the means to acquire their reactive capacity depending on: i) knowledge applicable to specific processes, ii) critical number of workers, employees and managers with such knowledge, iii) the regional educational and research infrastructure where technology in production is developed. All these three features provide the comparative advantages to the regional or technological cluster.

In a certain region of a CEM, for example in Guadalajara, organizations are constantly competing, against similar groups in other regions, to gain the production of new products. This situation makes the knowledge sharing process among all the involved parties, even among the competitors, a more relevant issue to the managers who know that the knowledge sharing process is needed to make the cluster more competitive.

The above presents a dilemma. The interest of local organizations to share knowledge on a regional basis in order to become more competitive, even among competitors, may conflict with the interest of global knowledge sharing, in the supply chain as a whole, as it could mean loss in their volume of production (Figure 1).

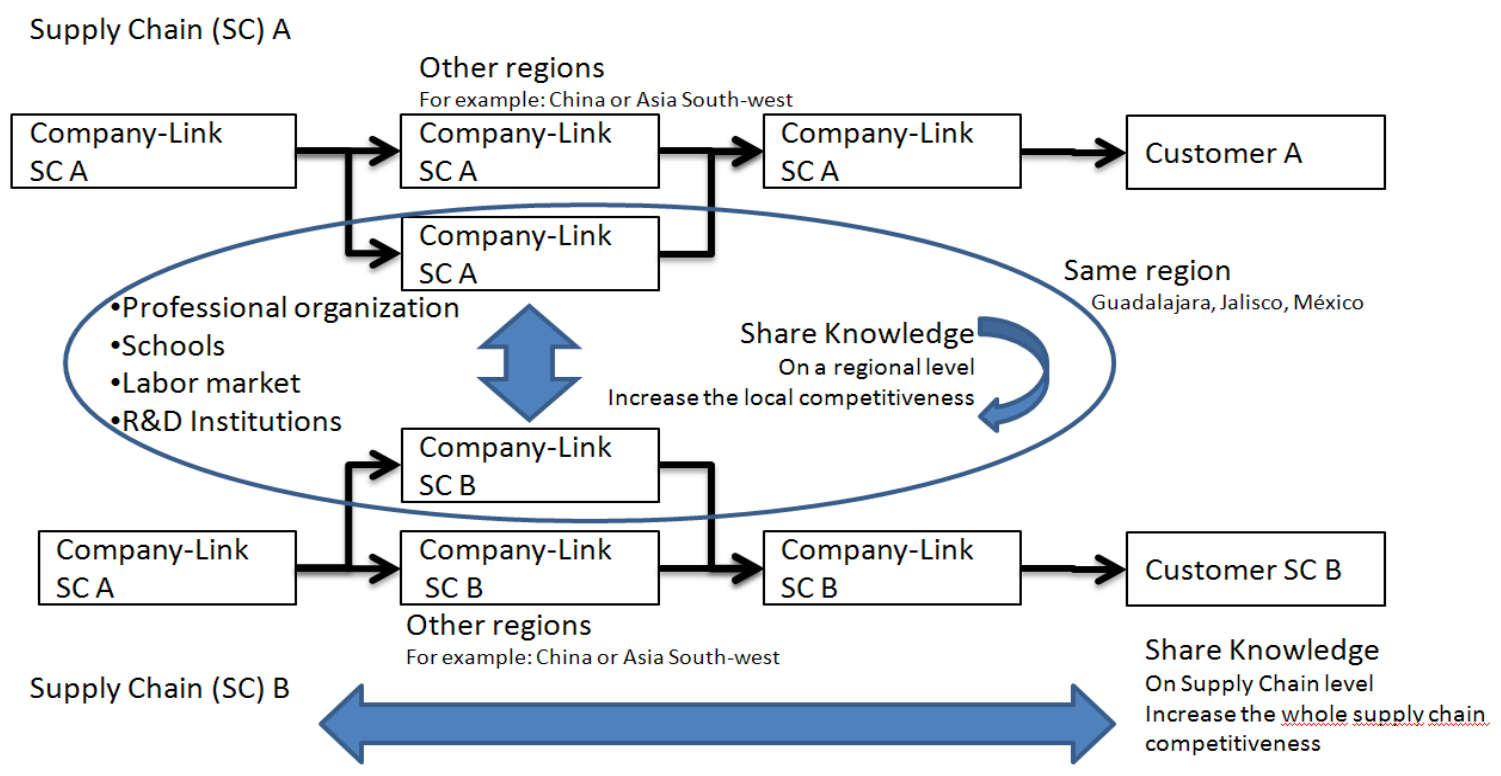

Figure 1. Knowledge transfer, at a regional level, for regional development. Conflict among competitors, situation that requires the intervention of organizations or neutral mechanisms. Source: Author. 
Understanding the knowledge transfer mechanisms and the knowledge generation processes may help to develop policies and resources to empower the cluster evolution, therefore the dilemma faced by the cluster manager would fade. This concept applies particularly to Contract Electronics Manufacturing (CEM) organizations.

The country, and in particular the State of Jalisco, would be interested in having competitive supply chains in the cluster; however, they would strongly prefer, when compared to China or Southeast Asia, to have such competitiveness mostly in their local organizations as it would mean they could target more of a market share.

\section{The Electronics Manufacturing Cluster In Guadalajara, Jalisco, Mexico}

In Mexico, within the North American region, the electronics manufacturing cluster in Guadalajara stands as an example of national industrial development immersed in the global economy. The study of the Guadalajara cluster would show the trends of its evolution and consequently its competitive potential would become even more evident.

In the scheme of outsourced supply chains, the development of new models and electronic devices, which are the result of technology convergence, seems to be a work generator for the CEMs operating in the Guadalajara cluster. This particular situation is highly relevant for the state's economy, as in 2008 such manufacturing accounted for around 70\% of the state's exports (Hisamatsu, 2008).

Such a trend has clearly affected the evolution of the operations in Guadalajara. This is a true reflection of the globalization in the sector; the ability to evolve in process and product design knowledge in the digital technology convergence represents a crucial variable in global competition. In this evolution three stages are defined: i) the first one, in the 70s and early 80s, when companies with Original Equipment (OEM) such as HP, IBM and Kodak arrived; ii) in the late 90s and the beginning of the next decade, when Contract Electronic Manufacturing (CEM) companies such as Flextronics, Jabil, Sanmina-SCI or Solectron settled; and iii) as of 2000, manufacturing services companies, created with foreign and national capital (Partida R., 2004).

\section{RESEARCH OBJECTIVES}

Within the electronics manufacturing cluster in Guadalajara Jalisco, Mexico, and particularly in the contract manufacturing (CEM) companies context, this research will study the role played by the knowledge transfer mechanisms involved in the manufacture reactive capacity needs, which result from the technology convergence trends. Moreover, this study will also consider the supply chain evolution that allows appropriate responses at the initial phase of a product life-cycle when the level of demand uncertainty is high.

\section{METHODOLOGY}

This paper intends to show, in its initial exploring phase, the results of a bibliographic review, which then will be complemented with the analysis of six cases and reports from outsourcing global supply organizations. The cases and reports are relevant as the communication process among all the company-links is regarded as an essential factor to empower reactive capacities of production in Mexican companies. Such cases and reports were produced in the period between May 2004 and April 2010, and they were selected, from a larger number, based on their relevance regarding contract electronics manufacturing (CEM) and their involvement in the electronics industry cluster of Guadalajara. Due to the information confidentiality policy, the names of the companies will be removed from three of the five reports (Estrada M., 2005) (Anaya, 2010) (Carral, 2007) (Huckman, 2006) (García, 2010).

\section{THEORETICAL FRAMEWORK}

The main bibliographic sources in the production of this paper are: (i) the research on the most efficient supply chains by Professor Hau Lee of Stanford University (2002) (2004), whose research addresses the concept of supply chains type "AAA" and the alignment of the supply chains with the demand uncertainty; and (ii) the research by Myers \& Cheung from the University of Tennessee, published by MIT Sloan Management Review, whose research addresses the role played by knowledge transfer in the supply chain evolution. Such research also describes 
the classification made on the type of knowledge to be shared and evaluates the impact that is caused by knowledge transferred depending on the way it is shared (Myers \& Cheung, 2008).

Kopzack \& Johnson proposed a change of perspective related to the supply chain management concept which identified continuous evolution on two levels. On one level we can expect more of the same. On another level, supply-chain management will affect industry structure and will create a new set of winners and losers (Kopczack, 2003).

An additional bibliographical source is the work by Fisher, Hammond, Obermeyer and Raman; their research focuses on the role played by the supply chain design as a means to synchronize itself with the demand in a world of great uncertainty (Fisher, Hammond, Obermeyer, \& Raman, 1994).

Finally, some concepts regarding the understanding of the mechanisms that generate trade associations and public bodies were gathered from Hisamatsu's work, which analyzes the role played by Western CANIETI and the CADELEC (Hisamatsu, 2008).

\section{DATA ANALYSIS}

\section{Reactive Competitive Capacity}

The most effective or competitive chains are not those that manage the lowest costs or those that offer the more rapid response, both standard conditions used to evaluate the logistics systems. Instead, the best supply chains are those that are agile, adaptive, and aligned with all the links in the chain; such features provide competitive advantages to meet demand. These supply chains are classified as "AAA supply chains". The feature "agile" refers to the supply chain's capacity to react to the constant changes in demand trends; the attribute "adaptive" refers to the supply chain's capacity to achieve a competitive position in an environment of constant changes to the industry structure; and the feature "aligned" refers to the homogeneity in objectives within each link of the whole supply chain (Lee H., 2004).

Such an approach shows the way globally competitive companies, such as Inditex, Seven-Eleven or Procter \& Gamble, have come to renew their supply chains by innovating their processes and putting aside the classical parameters; instead, they see the supply chains from a more holistic conceptualization (Ketchen, Rebarick, Hult, \& Meyer, 2008).

In the consumer electronic products, life-cycles are becoming shorter; moreover, the rapid changes in the demand volumes and the management of demand uncertainty have caused the reconfiguration of the supply chains, and the participants and regions are dynamically adapting to market conditions.

Suitable configuration models in supply chains are needed in order to compete. From that perspective, two different reactive capacity configuration models have been identified (Figure 2 and 3):

manufacturing capacity that meets speculative demand forecast; it takes advantage of stable production runs, usually long, with few product changes; this capacity utilization is more efficient and can be even more successful by lowering labor costs.

(ii) manufacturing capacity that reacts to demand information; production is based on early demand forecasts in which response time plays an important role; moreover, variable volume and product changes on the production lines mean shorter runs where the use of full capacity is not required (Fisher, Hammond, Obermeyer, \& Raman, 1994).

Such conceptualization would lead to believe that there are certain regions, clusters, or industries that are more competitive by having a reactive production capacity, and others in which competitiveness is achieved by a speculative production capacity. 


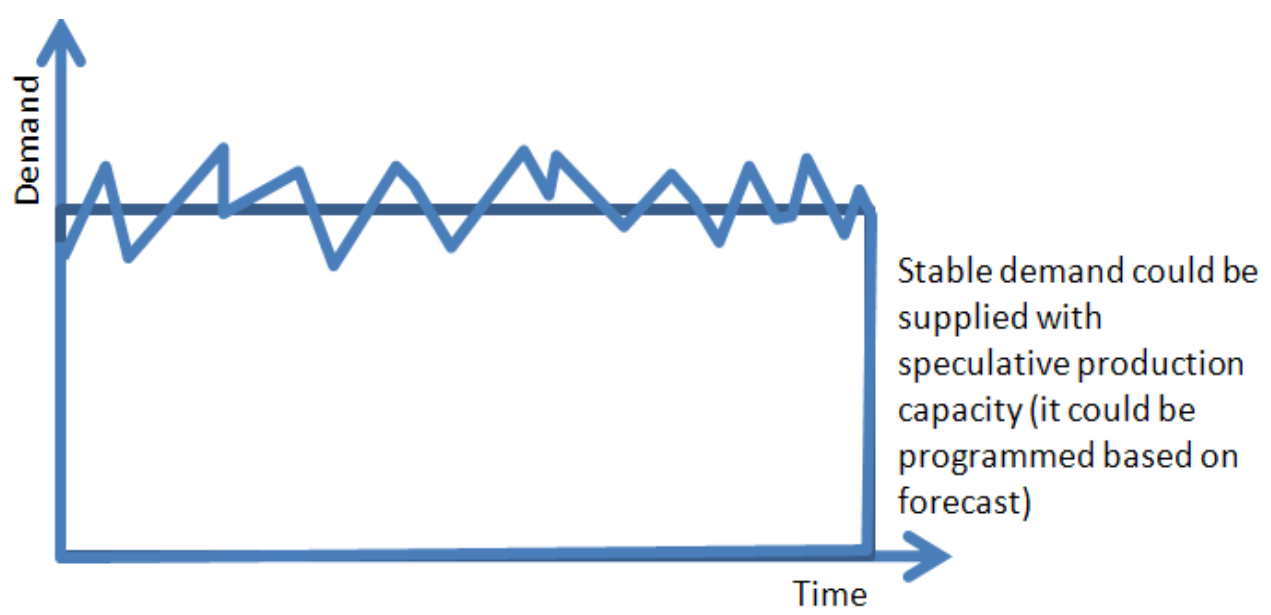

Figure 2. Stable demand that could be supplied in advance based on the forecast with low uncertainty. Source: Author based on Hau Lee.

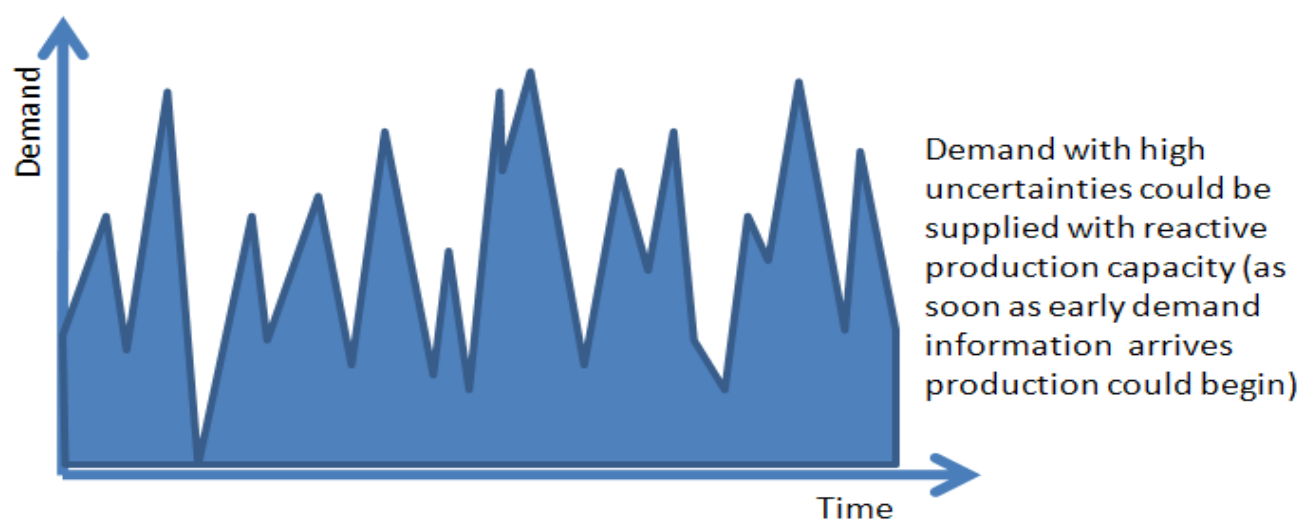

Figure 3. High uncertainty demand that could be supply based on early market information or orders. Usually requires rapid response and flexibility. The kind of production capacity that could cover this situation is reactive. Source: Author based on Hau Lee.

Mexico represents a central location for different global supply companies; Mexico's location and its proximity to the U.S. market help to maximize the reactive production responses. This implies, for the Guadalajara cluster, that the cluster's reactive capacity and specific knowledge transfer processes related to this kind of production capacity (reactive) are competitive advantages.

\section{Knowledge Transfer}

Matthew \& Cheung, from the University of Tennessee, and using the concept presented by Hau Lee, conducted an investigation into five companies, and over a hundred of their suppliers, with international operations. They concluded that knowledge transfer among all the links in the supply chain is an essential factor in the development of "AAA" supply chains (2004). However, the benefits received by all the links in the chain will not always be the same; such results will depend on the type of knowledge that is being transferred, the cultural differences involved, and the external conditions that affect the knowledge transfer. Sharing knowledge between firms is a controversial issue, despite the fact that the firms belong to the same supply chain. Among the main reasons why knowledge is not shared, there is a general idea that regardless of the method used in the knowledge transfer, such knowledge could end up with current or potential competitors; such concern becomes relevant as given the increase in competitiveness in the market, the units (links) in the supply chain, are conservative with respect to knowledge transfer as they aim to gain a larger share in the market (Myers \& Cheung, 2008). 
Sharing knowledge is needed for the supply chain in order to achieve such capacities (speculative or reactive). Such knowledge sharing is required among all the different links: organizing internal joint teams and sharing knowledge among customers and suppliers (cultural), situations that would not necessarily bring the same results, or simultaneously, to all the parties involved (Myers \& Cheung, 2008).

Knowledge transfer is an important factor in the evolution of the supply chain. Knowledge transfer creates the basic mechanisms for the supply chain to achieve its evolution, consequently making it more efficient. Nonetheless, inside the companies, the process of knowledge transfer is thought to be a double-edged sword that causes or increases competition (Myers \& Cheung, 2008).

However, for the regional clusters, sharing information with specialists from competitor companies is significantly relevant; furthermore, joining capacities with schools and local institutions plays an important role for the cluster's body of engineers and technicians (Hisamatsu, 2008).

Just as products are evolving, so are the structures of the CEMs. Their evolution involves the migration of value-added processes to regions or clusters where they can be more efficient. In this scheme, the competitiveness of a region is largely achieved by its ability to have its knowledge transfer mechanisms evolve. This evolution would allow the region to compete efficiently according to its planned strategy.

Apparently, in the Guadalajara cluster, the knowledge related to fast changes in product lines, flexible manufacturing, quick response manufacturing $(\mathrm{QRM})$, production cells, and product technologic platforms, among others, stands as a key element in the development of the reactive capacity of the cluster. Therefore, and according to the classification of Myers and Cheung (Myers \& Cheung, 2008), the evolution's importance lies in knowledge transfer, forming joint teams and promoting cultural integration.

\section{Electronic Products And Technology Convergence}

Technological electronic consumer products tend to migrate from low-volume operations, in which reactive, flexible, and rapid responses are seen, to high-volume operations, in which product design changes are made (i) to facilitate manufacturing and distribution and (ii) to reduce costs. (Low-volume operations, themselves, tend to involve a wide range of products at the initial stage of their life-cycle.)

The phenomenon of technology convergence favors platforms where other applications could be performed to create multifunctional devices (Ramos M., 2007). A clear example of this phenomenon is the cell phone; over time, various devices have been added to the cell phone, increasing its functions and applications. A cell phone is now a sophisticated communication device that includes computing capabilities that support software applications, GPS functionality, connectivity to Internet and increasingly improved screens on which it is possible to download information either from the internet or television. Each application involves a new reconfiguration of the supply chain and the development of operational strategies for the next phases of introduction. Therefore, it is possible to see various products being manufactured, such as the Xbox games (Lee H., 2006) in early stages (later the production was migrated to China, where labor rates are up to 40 times lower compared to Mexico, see e.g., Barber, 2005). This situation apparently happened in convergence smart cell phones such as the Blackberry and television satellite signal receivers, for example (Martínez, 2009).

\section{The Supply Chain Evolution}

A trend in the consumer electronics sector supply chain evolution is the inclusion of operations outsourced by Contract Electronic Manufacturer (CEM) companies for Original Equipment Manufacturers (OEM) companies.

A company may have acceptable levels of productivity without being competitive in the company's market context, and also, another company with lower productivity levels might be competitive in a specific market with and remarkable product (Barber, 2004). The CEMs have evolved from merely traditional electronics manufacturers, with contractual operations (Contract Manufacturer, CM), to more complex operations as product design (Design and Contract Manufacturer, CDM). Such a scheme has taken one more step; the product design is done by the 
contractor as per own initiative and then the product, with the integration of the entire supply chain, is sold (Original Design and Manufacturer, ODM ) (Huckman, 2006). Furthermore, with the development of a brand (Original Brand Manufacturer, OBM) the product can be directly offered to the final consumer.

This evolution is due to a competitive factor; as long as the integration of the supply chains continues, economies of scale will be achieved as well as advantages of information coordination and logistics; consequently business intelligence will be increased. Each stage has increased their service value content (Figure 4).

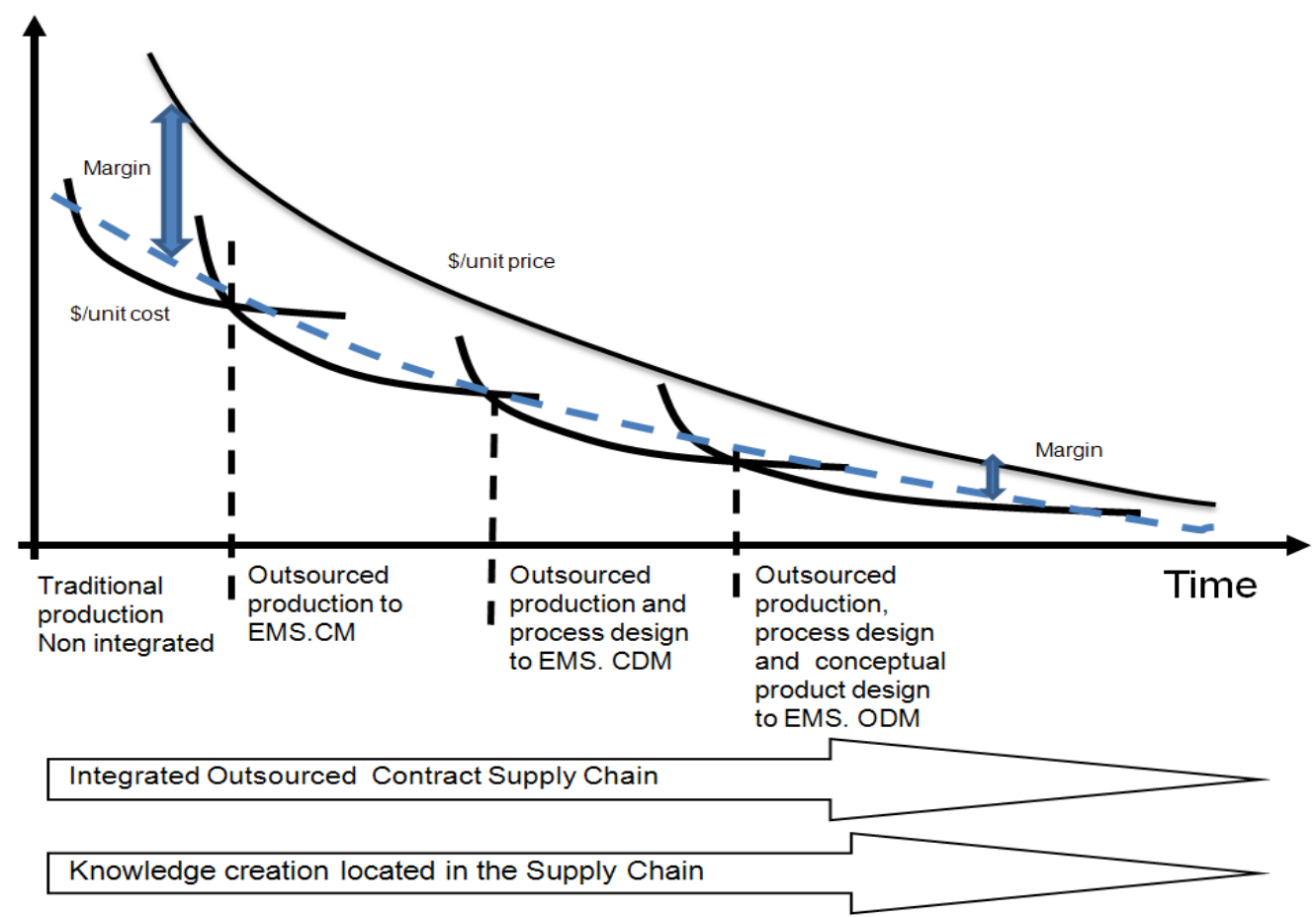

Figure 4. Supply Chain Evolution. Adapted by the author (Huckman, 2006).

Guadalajara, in Mexico, has been an appropriate location for CEM operations. Guadalajara has evolved as an industrial high-tech cluster, similar to Hong Kong, Penang, Malaysia, Guangdong, China or Dublin (Hisamatsu, 2008). The region features characteristics that would attract reactive capacity operations, ideal for technological products at the initial stage of their life-cycle.

The operation capacities in the supply chain have had to evolve by integrating into their processes the production processes, logistics, and design services. The CEM have evolved from the traditional manufacturing to CM, CDM, ODM and OBM (Huckman, 2006).

This phenomenon is not unique to Guadalajara, Jalisco. In places like Hong Kong, where the CEM performs daily operations, its contribution to add value to the business has been sought; such contributions would allow it to migrate to other stages of the supply chain and to improve its productivity

(HKTDC, 2008). See Figure 5.

When analyzing the role of the manager in the evolution process from the OEMs to outsourcing the CEMs, it is common to see that the CEMs buy the operations and production assets of the OEMs in exchange for contracts that give them access to international funding mechanisms. In many cases the managers of the firms acquired by CEMs are retained. The funding mechanisms allow the OEMs to gain access to cash flow while getting rid of necessary operations that do not add differential value, when compared to the competitors, thus allowing them to 
focus on strategic activities. Having explained the above, it is possible to see how the marginal role of the OEMs operations becomes essential to the CEM as such operations represent the CEM's core business and its means to compete.
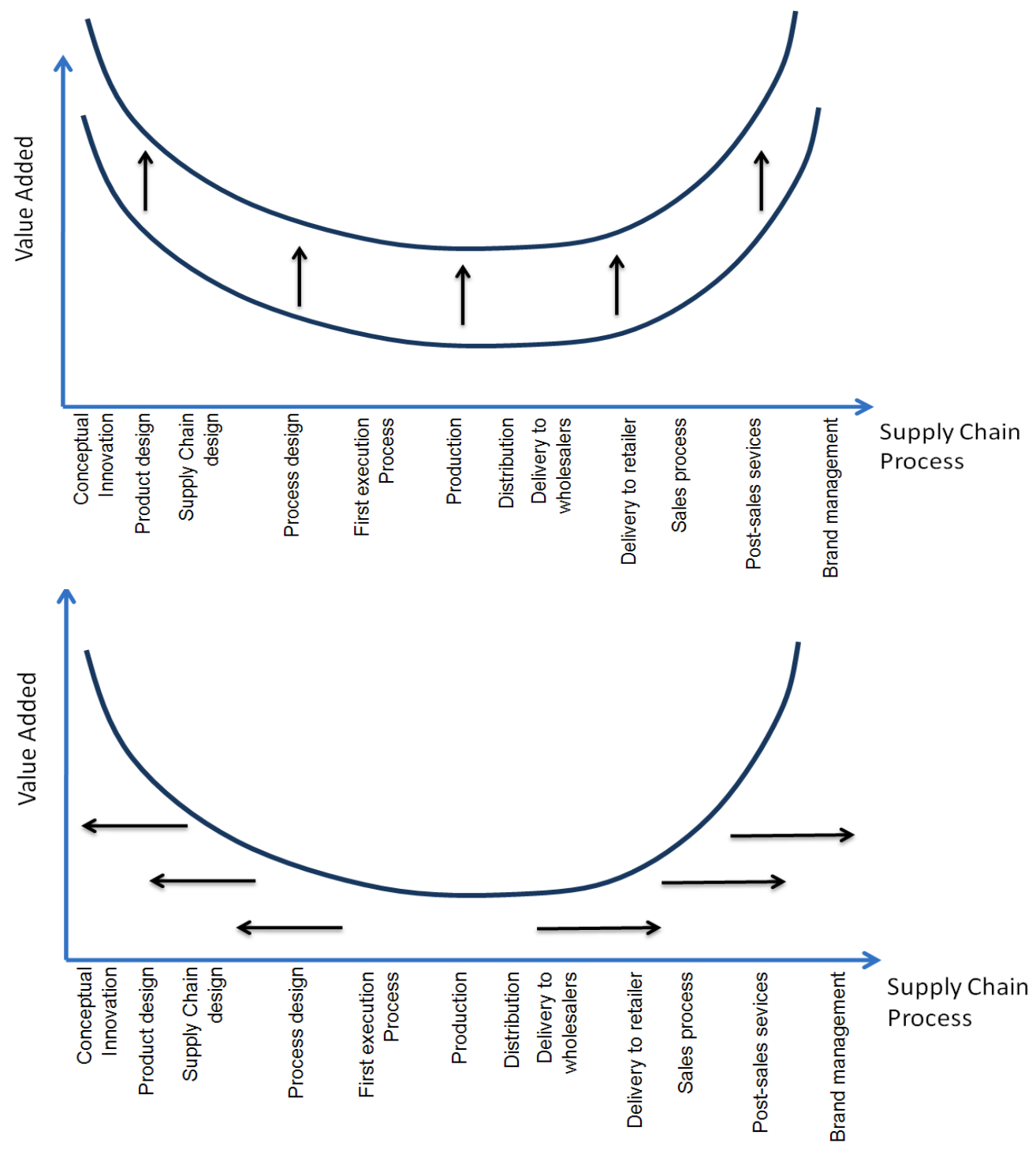

Figure 5. Strategies to increase value added through integration (top); and the value increase (down) for Hong Kong CEMs (HKTDC, 2008).

The level of performance expected from the managers becomes very relevant in the operation; their performance is easily comparable with others who have similar operations and this comparative process implies a noticeable internal competition. One interviewee, whose details are omitted, stated: "my real competitor does not lie in the similar operations of the competition, but in my colleagues in China, India, or Costa Rica. If they achieve better operations results than mine, then we will be closed down".

\section{The Knowledge Transfer Mechanisms In The Electronics Manufacturing Cluster Of Guadalajara}

The literature reviewed and the analysis of cases identifies the mechanisms by which the cluster of the electronics manufacturing industry in Guadalajara has developed and transferred specific knowledge in order to compete, by the reactive production capacity, in a local environment among competing companies. 
The knowledge transfer mechanisms are needed to increase the competitiveness in the cluster regardless of the competition among its local companies. For the operations managers and staff it is important to achieve regional competitiveness as they are constantly competing among similar operations of the CEM, but in different regions (China and Southeast Asia) in order to gain the manufacturing of the same products.

One of the identified mechanisms are the Chambers of Commerce, public bodies such as West CANIETI and CADELEC; these organizations not only bring together managers from competing companies, but also promote the creation of local suppliers and local manufacturing capabilities. In addition, the representativeness of the Chambers allows the coordination of undergraduate programs, specific to the regional needs, among existing universities. Similarly, the Chambers create Institutes whose purpose is to develop and to disseminate specific knowledge.

Another non-formal mechanism is the one created by job rotation; in this mechanism, the culture among employees and knowledge concerning the companies they have previously worked for is shared; although an informal mechanism, it shows high mobility on the labor force in the reactive capacity of the sector (García, 2010).

The conceptualization of suitable manufacturing models to respond to products with high level demand uncertainty, at the initial stage of their life-cycle, pushed the Guadalajara sector to develop knowledge transfer mechanisms.

To do so, the public associations, that bring together groups of managers and technicians, have developed key activities. These activities are centralized in professional associations such as:

i) the National Chamber of Electronic Industry, Telecommunications and Informatics, Western Regional Delegation (West CANIETI), in which companies' managers and managers from one of its specialized branches participate.

ii) the Electronics Supply Chain, AC (CADELEC) which seeks to develop local supply for the industry; additionally, one of its main objectives is to create business intelligence to identify the demand for certain products and recognize potential customers and suppliers. This organization acts as a neutral coordinator to empower the activities of the cluster.

These organizations promote, among the five main universities in Guadalajara, professions with industryspecific practices. The results of such promoting activities are the incorporation of another neutral actor that generates specific knowledge related to the strategic competences of the region. The research institutes that are related to this sector are also associated with such organizations (Hisamatsu, 2008). These neutral professional organizations could act with more freedom and be more focused.

Other non-formal mechanisms of sharing knowledge in the sector are the result of managers and technicians mobility in the labor market, in which shifts in job positions among different companies, cause sharing knowledge in the networks formed by moving from one company to another (Hisamatsu, 2008).

One manager said:

I had the unpleasant experience of closing a OEM plant. It was traumatic, but we could see how the 5,000 people fired were incorporated by other companies or by new industries, such as the software, services, aeronautic, or biomedics. New branches of high specialization that nowadays are the future of the Guadalajara cluster.

In addition to the scheme presented, it could be emphasized that the main advantages are achieved when the knowledge transfer focuses on specific skills providing strategic competencies. In the Guadalajara cluster situation, it is possible to identify that the cluster empowers itself by developing manufacturing capacities, with low volume and a wide range of products; such a condition allows the evolution of the supply chains simultaneously with the needs created by the technology convergence. In other words, enabling a rapid response to the market with high flexibility for the first production run on new products, whose level on demand uncertainty is high. This situation drives the advantage of being close to the main clients located in the United States. 
An additional element focuses on the different levels on knowledge transfer mechanisms: data, technological processes, and cultural aspects. In this regard, and at the regional level, the cultural exchange (related to continuous improvement and institutional discipline) as well as the technological processes, appear to have greater impact.

These characteristics, knowledge transfer, cultural aspects, or technological processes, focus on providing supply reactive capacities and integration in the supply chains; these elements, from the competitiveness of local operations, favor the evolution of the global supply chains.

\section{RESULTS}

\section{Knowledge Transfer For Reactive Capacity In Guadalajara}

Knowledge transfer in the Guadalajara cluster is an element that has determined the cluster's evolution. The traditional maquila has evolved, the most notable feature being that the value added it provides has increased; its evolution from first production operations to product design operations with lower costs shows the clear progression from $\mathrm{CM}$ to $\mathrm{CDM}$, and even to MDG.

From a global perspective, competition in the cluster is due to the efficiency of its local supply chains; however, this is also achieved by the development of local capacities aimed at empowering the production of the reactive type.

The findings suggest that knowledge transfer is needed for the cluster to evolve. Sharing knowledge should be at a regional level, among the suppliers, clients, and even the competitors. For that purpose, there is a need for neutral actors such as: (i) public associations, (ii) governmental institutions, (iii) educational and research organizations; such actors would enable the generation and transfer of knowledge to the people who run and operate the company.

Another non-formal mechanism is the job rotation in the work force, which moves through various companies; this condition has allowed the evolution of operations, managing to adapt to the different stages of the evolution in the supply chains. One thing to highlight is that although the evolution of the chains has led from OEM to CEM and later to locally-based suppliers, there are still traditional operations from the OEM and CEM mainly focused on their critical or strategic processes. Part of the importance of this phenomenon is that several of the activities were done in other countries; therefore, studying their migration to Guadalajara, in Mexico, would also imply the analysis of the evolution of its contribution to local value (Figure 6).

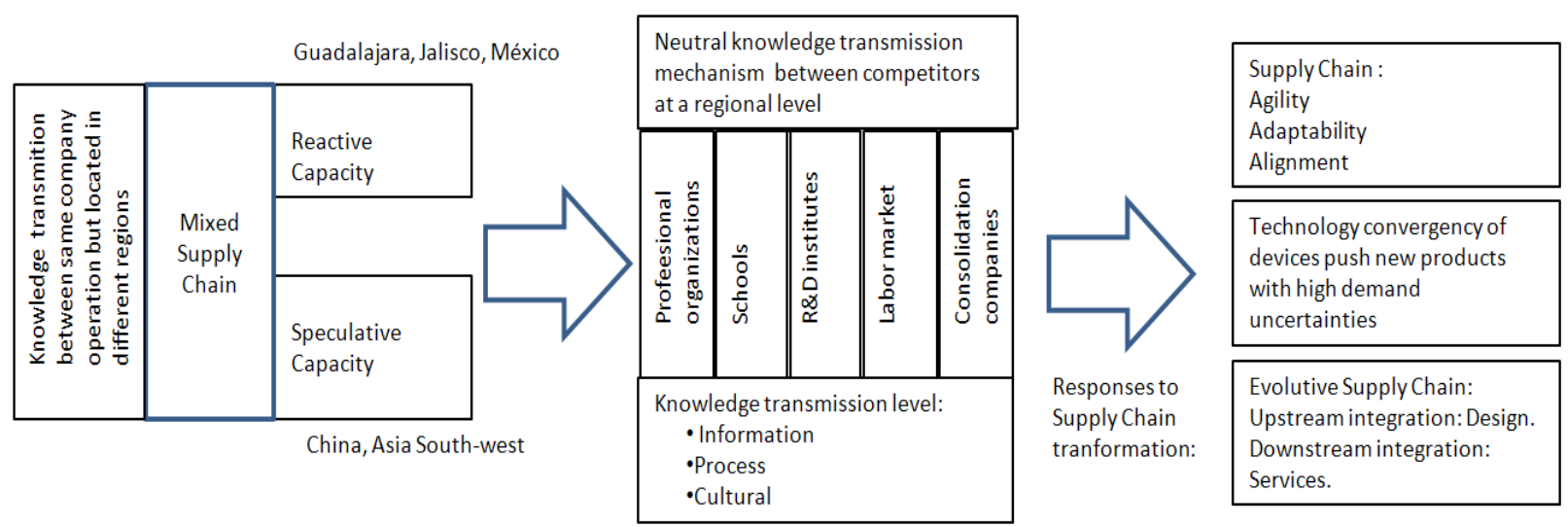

Figure 6. Knowledge transfer within the company and among different regions, compared to the knowledge transfer among the same regions. 


\section{CONCLUSIONS}

Mexico has managed to place itself in the economy of globalized production from local operations in Guadalajara. Despite the increasing competitiveness from other competing regions such as China and Southeast Asia, CEM companies continue with operations in Mexico, and such companies even play a strategic role.

Given the constant evolution of global electronic manufacturing industry, the operations in Guadalajara, to remain competitive, it can only be deduced that such operations have also evolved fast enough. Understanding that role, and the mechanisms that have allowed these developments, is essential to comprehend the basis of competition and thereby empower such mechanisms properly. In an evolutive chain, competitiveness is achieved by the chain's ability to evolve and to generate an environment of relevant knowledge, mainly related to the cluster's competitive strategy.

In particular, demand reactive capacity is important for product supply strategies in the convergence of electronic devices; it is also especially important to Guadalajara to promote the comparative advantages of its proximity to the main device developers located in the US market.

The cluster of electronics manufacturing industry in Guadalajara can show how these mechanisms have helped the cluster to evolve and how such mechanisms can be developed and applied to other regions or sectors.

\section{ACKNOWLEDGEMENTS}

Miguel Estrada Guzmán thanks Carlos Barber Kuri, his Ph.D. advisor, and Bo van der Rhee for their useful comments and suggestions for this research.

\section{REFERENCES}

1. $\quad$ Anaya, A. (2010). Abastecimiento de Componente Electrónicos. Reporte. No publicado.

2. Barber, C. M. (2005). China a la Conquista. Integra (5), 7-9.

3. $\quad$ Barber, C. M. (2004). Globalización y el Reto de la Competitividad. (3), 6-8.

4. Carral, J. (2007). Alterando la genética de negocio. Guadalajara, Jalisco, Mex.: Reporte. No publicado.

5. $\quad$ Estrada M., L. M. (2005). Flextronics Aguascalientes. Caso IPADE ((P)P-686).

6. $\quad$ Fisher, M. L., Hammond, J. H., Obermeyer, W. R., \& Raman, A. (1994, May-June). Making Supply Meet Demand in an Uncertain World. Harvard Business Review , 83-93.

7. Fundación Premio Nacional de Tecnología, A. C. (2009). Premio Nacional de Tecnología, Guía de participación 2009. México, D.F.

8. García, J. L. (2010). Redefiniendo la forma de la Cadena de Suministros. Guadalajara, Jalisco: Reporte. No publicado.

9. Hisamatsu, Y. (2008). The Evolution of the High-Tech Electronics Cluster in Guadalajara, Mexico. In M. T. Akifumi Kuchiki, The Flowchart Approach to Industrial Cluster Policy (pp. 262-281). Ide-Jetro Palgrave MacMillan.

10. HKTDC. (2008, Febrero 18). Study on OEM, ODM and OBM: Extending the Supply Chain with Added Value. Retrieved Abril 25, 2010, from Hong Kong Trade Development Council: http://www.hktdc.com//info/vp/a/hke/en/1/4/1/1X0040U6/Study-On-OEM-ODM-And-OBM-ExtendingThe-Supply-Chain-With-Added-Value.htm31\#

11. Hong Kong Trade Development Council . (2008, Febrero 18). Study on OEM, ODM and OBM: Extending the Supply Chain with Added Value. Retrieved Abril 25, 2010, from http://www.hktdc.com//info/vp/a/hke/en/1/4/1/1X0040U6/Study-On-OEM-ODM-And-OBM-ExtendingThe-Supply-Chain-With-Added-Value.htm31\#

12. Huckman, R. S. (2006). Flextronics Internationa, Ltd. Harvard Business School Case Study (9-605-S06), 2004.

13. Ketchen, D. J., Rebarick, W., Hult, T., \& Meyer, D. (2008). Best value supply chains: A key competitive weapon for the 21st century. (I. U. Kelley School of Business, Ed.) Elsevier. Business Horizont (BH 279), 235-243. 
14. Kopczack, L. R. (2003). The Supply-Chain Management Effect. MIT Sloan Management Review , 44 (3), 27-34.

15. Lee, H. (2006). Evolution of the Xbox supply chain. Case, Stanford Graduate School of Business.

16. Lee, H. L. (2002). Aligning supply chain strategies with product uncertainties. California Management Review , 44-3 (Spring), 105-119.

17. Lee, H. L. (2004, October). The Triple-A Supply Chain. Harvard Business Review , 4-14.

18. Martínez, A. L. (2009). Los que mejor sortearon la crisis. (G. E. Expansión, Ed.) Expansión (1026), 103106.

19. Myers, M. B., \& Cheung, M.-S. (2008). Sharing Global Supply Chain Knowledge. MIT Sloan Managemente Review , 49-4 (SMR289), 67-73.

20. Ornelas, S. (2009, July-August). Logistics Mexico's Life Buoy. Mexico Now , 41-3.

21. Partida R., R. E. (2004). Effects of the globalization on the workers of the electronics cluster in Jalisco, México. In Research in the Sociology of Work (Vol. 13, pp. 125-140). México: Elsevier Ltd.

22. Ramos M., J. L. (2007). La convergencia tecnológica, Tecnologías digitales y telecomunicaciones. In F. Gonzalez Luna, G. Soria G., \& J. Tejado D., La regulación de las telecomunicaciones (pp. 23-33, 373390). México: Miguel Ángel Porrúa. 